\title{
A INTERVENÇÃO ESTATAL NO MERCADO COMO ACIONISTA DE EMPRESA PRIVADA E A EXIGÊNCIA DO PROCESSO LICITATÓRIO PARA ALIENAÇÃO DA PARTICIPAÇÃO SOCIETÁRIA
}

Marcos Henrique Silvério ${ }^{1}$

\section{RESUMO}

O artigo 37, XX, da Constituição Federal permite a participação estatal em empresa privada. É uma forma relevante de intervenção no mercado, de desenvolvimento econômico-social e de fomento da empresa. Os artigos 37, XXI, e 173, § $1^{\circ}$, inciso III, da Constituição Federal determinam a licitação para a alienação. O objetivo será analisar os limites e a natureza dessa intervenção, se é aplicável o regime de direito público na empresa privada após ingresso do acionista estatal e a exigência da licitação para alienação das ações. Optou-se pelos métodos indutivos e dialéticos, a partir da pesquisa básica, qualitativa, descritiva e bibliográfica.

PALAVRAS-CHAVE: Participação. Estado. Empresa privada. Alienação. Licitação.

\section{STATE INTERVENTION IN THE MARKET AS A SHAREHOLDER OF A PRIVATE COMPANY AND THE REQUIREMENT OF THE BIDDING PROCESS FOR THE SALE OF THE EQUITY INTEREST}

\begin{abstract}
Article 37, XX, the Federal Constitution allows state participation in private enterprise. It is a relevant form of market intervention, economic-social development and enterprise development. Articles 37, XXI and 173, paragraph 1, item III, of the Federal Constitution determine the bidding for the sale. The objective will be to analyze the limits and the nature of this intervention, if the public law regime in the private company is applicable after joining the state shareholder and the requirement of the bidding for the disposal of the shares. Inductive and dialectical methods were chosen based on basic, qualitative, descriptive and bibliographic research.
\end{abstract}

KEYWORDS: Participation. State. Private company. Alienation. Government acquisition process.

\section{1 - INTRODUÇÃO}

A reflexão proposta neste artigo foi extraída a partir de uma observação empírica.

O empresário relatou que a sociedade anônima fechada familiar da qual é acionistafundador estava gerando lucro e empregos e estava pagando em dia as obrigações, mas queria expandir os negócios. A referida companhia dedica-se a atividades tecnológicas e estratégicas para o desenvolvimento econômico-social regional e nacional e para a segurança nacional.

\footnotetext{
${ }^{1}$ Advogado. Mestrando pela Faculdade de Direito da Milton Campos. LL'M em Direito Corporativo pelo IBMEC. Graduado em Direito pela Faculdade de Direito de Pontifícia Universidade Católica de Minas Gerais. Endereço eletrônico marcos@ silverio.adv.br e endereço postal Rua Felipe dos Santos, nº 825, conj. 702/703, bairro Lourdes, Belo Horizonte, Minas Gerais, CEP 30.180-160.
} 
O empresário passou a considerar imperioso o ingresso de um sócio "estratégico", com participação acionária minoritária e sem poder de controle, em razão de suas observações de empresas com atividades afins nos Estados Unidos da América. Na sua concepção, tal sócio deveria reunir atributos capazes para dar mais visibilidade à companhia nos cenários nacional e internacional, para dar mais credibilidade comercial e econômica sobretudo perante possíveis parceiros internacionais, para garantir competitividade internacional e interna, para fomentar a atividade econômica da companhia, investindo capital relevante e diretamente proporcional à importância da atividade e do projeto almejado e robustecendo a imagem empresarial com sinais de confiabilidade.

O mencionado empresário acreditava que o possível sócio que reunisse tais atributos agregaria elementos relevantes, levaria ao progresso da companhia e promoveria evidentes vantagens para o desenvolvimento econômico e social.

O empresário informou que havia conhecido tal sócio, já havia iniciado as tratativas, a due diligence tinha sido concluída e as condições comerciais para ingressar na companhia já estavam demarcadas focando no aumento do capital social com emissões de novas ações. Não haveria compra e venda de ações, pois o propósito era fomentar a atividade econômica, a capitalização e o fortalecimento da companhia. As avaliações e as diligências foram satisfatórias, indicando bom funcionamento e boas práticas de controles, especialmente financeiro e tributário, bem como boa gestão desempenhada por seu sócio fundador, sendo necessárias algumas adaptações de governança corporativa.

Indagado ao empresário quem seria o sócio, respondeu que seria uma empresa estatal integrante da administração pública que detinha permissão para participação em companhia.

Surpreendeu, pois, dentre os sócios com tais atributos pessoais, o Estado, quiçá, seria o menos ambicionado, sobretudo por eventuais déficits relacionados às finanças públicas, às eventuais interferências políticas e partidárias, à duvidosa eficiência administrativa e ao rigor do regime de direito público, especialmente mais austero do que o de direito privado e do que o direito empresarial, cujo funcionamento dinâmico conflita com procedimentos muitas vezes burocráticos e obstruídos exigidos da administração pública.

Havia a inquietação se a participação da empresa estatal poderia atrair para a relação societária e para a relação empresarial privada, cuja performance financeira era razoável e as perspectivas de crescimento eram aceitáveis, alguns abstrusos déficits de funcionamento da administração pública, bem como atrair o regime de direito público, como, por exemplo, as 


\section{A INTERVENÇÃO ESTATAL NO MERCADO COMO ACIONISTA DE EMPRESA PRIVADA E A EXIGÊNCIA DO PROCESSO LICITATÓRIO PARA ALIENAÇÃO DA PARTICIPAÇÃO SOCIETÁRIA}

regras de fiscalização e de controles financeiro, administrativo e patrimonial inconciliáveis com a dinâmica e a agilidade funcional das empresas privadas e do direito societário.

Afinal, o pretendido sócio integrava a administração pública e parte do capital social da empresa, a partir do ingresso do novo acionista estatal, ainda que minoritário, teria origem em recursos públicos.

Seria prudente melhor reflexão sobre a procura de outros possíveis sócios. Assim, as possíveis polêmicas seriam sobrepujadas. Todavia, considerando a atividade da companhia na área tecnológica e a finalidade da expansão internacional, seria difícil, talvez improvável, encontrar sócio detentor dos atributos instituídos, de maneira especial com intuito de fomentar a atividade econômica empresarial mirando a interesses públicos diversificados.

O empresário estava convicto dos benefícios que essa parceria poderia alavancar.

Foi solicitada a avaliação dos instrumentos jurídicos para a efetivação do negócio. A operação estava estruturada a partir do aumento do capital social da companhia e a emissão de novas ações ordinárias nominativas, sem valor nominal, com direito a voto, subscritas e integralizadas pelo acionista estatal, representativas de menos de $20 \%$ do capital social.

Também havia um acordo de acionistas, em que, dentre outras cláusulas, pactuou-se o direito de veto sobre algumas matérias relevantes e a participação minoritária no conselho de administração em benefício do acionista estatal minoritário, o direito de preferência na aquisição de ações, o tag along (direito de venda conjunta) e a opção de venda.

As indagações surgiram, isto é, se a empresa estatal poderia adotar aquela roupagem empresarial (participação acionária minoritária em empresa privada), quais os limites e qual a natureza dessa técnica de atuação do Estado, se seria aplicável o regime de direito público ou de direito privado na relação jurídica pós-ingresso do acionista estatal e, por conseguinte, qual seria o procedimento de alienação válida da participação societária do acionista estatal, cuja natureza jurídica era uma empresa pública.

O objeto do artigo cinge-se a esses problemas e, especificamente, visa a perquirir se, na relação jurídica delineada, após o ingresso do acionista estatal minoritário na companhia privada (sociedade anônima de capital fechado), seria aplicável o regime de direito público ou de direito privado. O estudo examina a hipótese se a relação jurídica ora especificada deve ser disciplinada pelas normas de direito privado, pois a companhia não se transformaria em ente integrante da administração pública, em razão da participação minoritária e sem poder de controle da empresa estatal. Esse é o tema central. Logo, o objetivo específico será investigar 
se as normas de direito privado é que postulam a incidência para regular a mencionada relação jurídica, sendo, por conseguinte, incabível exigir o processo licitatório para a alienação das ações adquiridas pelo acionista estatal quando do seu ingresso na companhia.

O estudo dessas questões é importante e justifica-se sob a perspectiva social e técnico-jurídica. A título de exemplo, a CODEPAR, subsidiária integral da CODEMINAS, informou nas demonstrações financeiras referentes a 2015, que "possui investimentos em participações minoritárias da ordem de $R \$ 106.355$ mil destinados ao fomento da indústria de alta tecnologia no segmento Aeroespacial e de Telecomunicações".

O tema realçou sua relevância com a promulgação do estatuto jurídico das empresas estatais (Lei Federal n ${ }^{\circ}$ 13.303, de 30 de junho de 2016) e pelo decreto que a regulamentou (Decreto $\mathrm{n}^{\circ}$ 8.945, de 27 de dezembro de 2016). Esse arranjo de participação acionária vem sendo adotado pela União para concessão dos aeroportos, em que a Infraero assume a posição de acionista minoritária das concessionárias.

A questão está permeada por proeminente debate ético, jurídico e social decorrente da aplicação de dinheiro público em empresas privadas. Está em evidência a operação Bullish, que investiga fraudes em aportes do Banco Nacional de Desenvolvimento Social (BNDES) ao grupo frigorífico JBS/Friboi, que, segundo foi divulgado na imprensa, podem ter produzido prejuízo de $\mathrm{R} \$ 1,2$ bilhão aos cofres públicos.

O Tribunal de Contas da União, em 18 de maio de 2016, deparou-se com a questão da participação societária de ente estatal em empresa privada e analisou a questão sob a ótica da impossibilidade de contratação direta dessas empresas sem licitação, conforme Acórdão 1220/2016, Ata 17/2016.

O tema também esteve sob análise na Ação Penal 470/MG (Mensalão) julgada pelo Supremo Tribunal Federal, sob a ótica da vinculação e da natureza dos recursos financeiros da empresa privada com participação estatal minoritária, a Companhia Brasileira de Meios de Pagamento - CBMP (VISANET).

O Supremo Tribunal Federal julgou a Ação Direta de Inconstitucionalidade 1.923, em que, apesar de a matéria de fundo dizer respeito somente às Organizações Sociais, o tema está inserido em contexto mais abrangente e de suma importância para o alcance dos objetivos do Estado no contexto dos limites da atividade administrativa de fomento.

Ademais, as disposições constitucionais conduzem a dúvida quanto à alienação da participação societária do ente estatal na empresa privada que não seja de capital aberto. 


\section{A INTERVENÇÃO ESTATAL NO MERCADO COMO ACIONISTA DE EMPRESA PRIVADA E A EXIGÊNCIA DO PROCESSO LICITATÓRIO PARA ALIENAÇÃO DA PARTICIPAÇÃO SOCIETÁRIA}

O artigo 37, XIX e XX, da Constituição Federal estabelece duas formas distintas de participação do Estado na economia. No inciso XIX, está previsto que: "somente por lei específica poderá ser criada autarquia e autorizada a instituição de empresa pública, de sociedade de economia mista e de fundação, cabendo à lei complementar, neste último caso, definir as áreas de sua atuação". No inciso $\mathrm{XX}$, existe previsão diferente: "depende de autorização legislativa, em cada caso, a criação de subsidiárias das entidades mencionadas no inciso anterior, assim como a participação de qualquer delas em empresa privada".

Em Minas Gerais, por exemplo, a Companhia de Desenvolvimento Econômico de Minas Gerais - Codemig está autorizada pela Lei Estadual 14.892, de 17/12/2003, nos termos do artigo $2^{\circ}$-A, III, a "participar em empreendimento econômico com empresas estatais ou privadas, mediante contrato de parceria e subscrição do capital social, nos termos do inciso XX do art. 37 da Constituição da República" (redação dada pela Lei Estadual 22.257, de 27/07/2016, que estabelece a estrutura orgânica da administração pública do Poder Executivo do Estado e dá outras providências). A Lei Estadual 19.965, de 26/12/2011, autoriza a Companhia de Desenvolvimento Econômico de Minas Gerais a constituir subsidiárias para participar de empresas privadas.

O artigo 173, caput, da Constituição Federal, por seu turno, estabelece: “Ressalvados os casos previstos nesta Constituição, a exploração direta de atividade econômica pelo Estado só será permitida quando necessária aos imperativos da segurança nacional ou a relevante interesse coletivo, conforme definidos em lei."

O artigo 37, XXI, da Constituição Federal prevê:

A administração pública direta e indireta de qualquer dos Poderes da União, dos Estados, do Distrito Federal e dos Municípios obedecerá aos princípios de legalidade, impessoalidade, moralidade, publicidade e eficiência e, também, ao seguinte: ressalvados os casos especificados na legislação, as obras, serviços, compras e alienações serão contratados mediante processo de licitação pública que assegure igualdade de condições a todos os concorrentes, com cláusulas que estabeleçam obrigações de pagamento, mantidas as condições efetivas da proposta, nos termos da lei, o qual somente permitirá as exigências de qualificação técnica e econômica indispensáveis à garantia do cumprimento das obrigações.

E o artigo 173, $\S 1^{\circ}$, inciso III, da Constituição Federal determina:

A lei estabelecerá o estatuto jurídico da empresa pública, da sociedade de economia mista e de suas subsidiárias que explorem atividade econômica de produção ou comercialização de bens ou de prestação de serviços, dispondo sobre: licitação e contratação de obras, serviços, compras e alienações, observados os princípios da administração pública. 
O artigo 17, II, “c”, da Lei 8.666/93 dispensa a licitação para a "venda de ações, que poderão ser negociadas em bolsa, observada a legislação específica”. O recorte realizado no presente estudo limita a análise à alienação das ações detidas em sociedade anônima fechada.

Quanto às ações adquiridas pela empresa estatal para formar a companhia públicoprivada $^{2}$ de capital fechado, as normas constitucionais não elucidam se devem ser alienadas também por processo de licitação pública, ou se o regime jurídico seria do direito privado ou, ainda, se seria aplicável a exceção prevista no artigo 17, II, “c”, da Lei 8.666/93. O impacto da resposta é real, sobretudo aos acordos de acionistas e à validade das cláusulas relacionadas à alienação da participação societária (preferência, tag along e put option v.g.).

Foram considerados os dados empíricos. Destarte, optou-se pelos métodos indutivos e dialéticos, a partir da pesquisa básica, qualitativa, descritiva e bibliográfica.

\section{2 - DESENVOLVIMENTO}

A Constituição Federal autoriza o Estado utilizar a instituição empresa privada à luz do artigo 37, inciso XX, da Constituição Federal, acima reproduzido.

A participação do Estado na empresa privada, conforme autorizado pela Constituição Federal e pela legislação própria, configura exploração de atividade econômica, tornando-o empresário, empreendedor e acionista. Apesar de fixados os limites pelo artigo 173, caput, da Constituição Federal para exploração direta de atividade econômica pelo Estado - imperativos da segurança nacional ou relevante interesse coletivo -, a mesma norma constitucional excetua: "Ressalvados os casos previstos nesta Constituição".

A hipótese do artigo 37, inciso XX, da Constituição Federal poderia ser concebida como exceção ao art. 173, caput, da Constituição Federal, permitindo, por exemplo, a atuação do Estado, por meio da participação em empresa privada, como investimento ou objetivando o lucro e o aumento patrimonial próprio. Ainda assim, essa atuação com a finalidade precípua de lucro e de aumento patrimonial não estaria totalmente desvestida de relevante interesse coletivo, porque o aumento patrimonial do Estado contribuiria para a distribuição de riquezas e melhor prestação dos serviços públicos essenciais, isto é, atenderia ao interesse público.

A Constituição Federal autorizou o Estado a ser acionista de companhia privada e, por conseguinte, a atuar como empresário e investidor. Não haveria iniquidade, improbidade

\footnotetext{
${ }^{2}$ Denominação adotada por ARAGÃO (2009) para designar a empresa privada com participação societária minoritária de ente público integrante da administração pública sem poder de controle. Consideramos relevantes as observações apresentadas SCHIND (2017), no que tange à terminologia empregada para se referir à empresa privada com participação estatal e, conforme será exposto, a rotulagem poderia ser evitada.
} 


\section{A INTERVENÇÃO ESTATAL NO MERCADO COMO ACIONISTA DE EMPRESA PRIVADA E A EXIGÊNCIA DO PROCESSO LICITATÓRIO PARA ALIENAÇÃO DA PARTICIPAÇÃO SOCIETÁRIA}

ou ilegalidade o Estado, que opta por ingressar na empresa privada, objetivar o lucro e a valorização patrimonial, tal como o empresário privado. Pelo contrário, os recursos públicos gozam de especial tutela jurídica e não podem ser dilapidados em iniciativas empresariais economicamente inermes, inexequíveis ou duvidosas, ainda que enaltecíeis sob a ótica social ${ }^{3}$.

A atração da lógica empresarial econômica, baseada no sucesso do empreendimento, no crescimento patrimonial e no lucro, demanda eficiência, competência e transparência. A atuação pautada nesses paradigmas exigiria escolhas melhores. $\mathrm{O}$ investimento de qualidade proporcionaria inovações de impacto (MAZZUCATO, 2014, p. 27) significativamente mais benéficas e mais valiosas para a coletividade a médio e a longo prazos.

A participação do Estado na companhia privada, sob a justificativa tão somente de fomento ou de assistencialismo, sem assegurar de que está realizando um bom negócio sob a ótica econômica e sem intuito de auferir frutos patrimoniais e financeiros, poderia abonar, à luz da Constituição Federal, a má gestão dos recursos públicos, o que seria inconstitucional.

A tipologia empresarial destinada à prestação de serviços públicos é outra. Não seria a investidura empresarial prevista pelo artigo 37, XX, da Constituição Federal. O arranjo para o Estado praticar atos de subvenção e de apoio financeiro, bem como assistencialismo social, não precisa ser, em juízo de adequação, por meio da participação empresarial privada.

Se essa for a espécie de fomento almejado, o empréstimo subvencionado, com acesso universal e igualitário, seria método adequado. Mas, se o Estado torna-se empresário, escolhe onde aplicar o dinheiro, sem processo seletivo público ou baseado em critérios estabelecidos, o interesse coletivo perpassa pelo intuito de crescimento patrimonial e de resultados positivos, mesmo que o escopo paralelo seja o desenvolvimento econômico-social ou o fiscalizatório.

O Estado empreendedor ou empresário ${ }^{4}$, se optou por usar essa roupagem de atuação constitucional, tem o dever de ser o investidor mais conspícuo, diligente e eficaz, equivalente, por exemplo, às instituições que administram e aplicam dinheiro alheio.

É certo que as empresas são susceptíveis a riscos e a perdas. Mas o que se pretende realçar é o fato de que o Estado empreendedor atua como empresário, e não como provedorpaternal-assistencial, isto é, tem ele o dever de identificar os riscos, de dosar as perdas e, sobretudo, de abster-se diante de situações incompatíveis com os princípios reitores do direito

\footnotetext{
${ }^{3}$ FIDALGO (2017, p. 26) menciona informações extraídas da ONG Contas Abertas no sentido de que a União teria participação societária de mais de $\mathrm{R} \$ 180$ bilhões em 2010, incluindo até fábrica de lingerie já fechada.

${ }^{4}$ A terminologia Estado empreendedor, Estado acionista ou Estado empresário é usada para referir ao fenômeno jurídico-constitucional da participação da empresa estatal na empresa privada, identificando a situação jurídica do ente público após a integralização do capital social na empresa privada.
} 
público, pois a Constituição Federal, ao mesmo tempo em que permite ser empresário, exige submissão aos princípios da proporcionalidade, da moralidade (transparência) e da eficiência.

A participação do Estado na empresa privada não pode ser concebida, pelas mesmas razões, como mera "fuga" para o regime de direito privado ou forma de libertação do regime de direito público e de condicionamentos em busca de processos mais eficientes. O ingresso na empresa privada atrai a lógica empresarial do lucro e do crescimento patrimonial, valendo destacar a observação de SCHWIND (2017, p. 67) no sentido de que "a adoção de formas jurídicas empresariais pelo Estado deriva de uma lógica atrativa da racionalidade empresarial como sendo a forma mais apropriada de atuação no domínio econômico".

ARAGÃO (2009, p. 8) refere-se aos motivos de participação do Estado em empresas privadas da seguinte forma:

De nossa parte, propomos a sistematização pela qual se dá a participação do Estado em empresas privadas de forma minoritária, seja: (a) para fomentar determinados setores da atividade econômica; (b) para realizar de forma mais eficiente as atividades-fim de suas sociedades de economia mista; ou até mesmo (c) para direcionar as atividades de uma empresa privada (eventualmente uma concessionária de serviços públicos), através de eventual titularidade de uma golden share ou da celebração de um acordo de acionistas.

FIDALDO (2017, p. 362), com base em Giuseppe Marcon, elenca os possíveis motivos para a participação estatal em sociedades privadas:

[...] (i) possibilitar uma maior fiscalização e determinado grau de controle sobre uma sociedade privada na qual o Estado possui especial interesse (seja concessionária de serviços públicos, sociedade estatal recém privatizada ou uma sociedade financiada pelo Estado); (ii) financiar uma atividade econômica explorada por determinada sociedade privada; (iii) explorar determinada atividade diretamente, em parceria com a iniciativa privada, com vista a dividir ônus e obter know how.

GUEDES (2015, p. 90) justifica a participação do Estado na empresa privada "com o objetivo de explorar diretamente uma atividade econômica em sentido estrito ou prestar determinado serviço público".

É evidente que não se almeja equiparar o Estado ao investidor particular, pois suas atribuições são diversificadas. Todavia, não é justificável obrigar o Estado, por ser o Estado, tolerar fracassos empresariais e amargar prejuízos às vezes elevados, previsíveis e escusáveis. Afinal, as funções de controle, de subvenção e de assistência podem ser exercidas sem o figurino empresarial privado, sem a exposição ao risco empresarial decorrente da participação

\footnotetext{
${ }^{5} \mathrm{O}$ termo foi utilizado sem nenhuma conotação pejorativa e sob a premissa de inexistência de improbidades.
} 


\section{A INTERVENÇÃO ESTATAL NO MERCADO COMO ACIONISTA DE EMPRESA PRIVADA E A EXIGÊNCIA DO PROCESSO LICITATÓRIO PARA ALIENAÇÃO DA PARTICIPAÇÃO SOCIETÁRIA}

societária na empresa privada. É nessa perspectiva que se entende que o Estado se instala como empreendedor-empresário ao fazer a opção consciente pela modalidade de intervenção prevista no artigo 37, inciso XX, da Constituição Federal e o interesse público torna-se parte indissociável da lógica empresarial econômica ${ }^{6}$.

RODRIGUES (2004, p. 143) não chega ao patamar de admitir o lucro como desígnio precípuo dessa sistemática de participação do estado em empresa privada, mas também não o afasta para conceber essa intervenção apenas como regulatória ou assistencial, afirmando que “a opção pelo Estado por formas jurídico-privadas, pressupõe um grau mínimo de perseguição de fins lucrativos dificilmente compatibilizáveis com objetivos de regulação".

Não é possível deixar de aderir, parcialmente, às constatações de MELLO (2011), aplicáveis no presente caso, ao confrontar as atividades de fomento e o princípio da isonomia:

Não é difícil perceber que a atividade de fomento oferece um vasto campo para que a Administração Pública atue ao arrepio do princípio da isonomia. Afinal, trata-se de uma atividade marcada pela concessão de vantagens e benefícios aos particulares que ajam em conformidade com o desejo estatal, que por conta de sua escolha recebem um tratamento especial, eventualmente prejudicial aos que não sucumbem aos incentivos oferecidos pelo Estado [...].

$\mathrm{O}$ maior risco à isonomia é que os benefícios e privilégios sejam distribuídos sem qualquer critério racional que justifique o tratamento diferenciado. [...] $\mathrm{O}$ exercício da atividade de fomento sem controles jurídicos pode levar a um Estado de amiguismo, obviamente incompatível com o Estado de Direito.

Faz-se uma análise preponderantemente pragmática-econômica, consentânea com a lógica empresarial. O Estado empreendedor, que racionalmente opta pelo modelo empresário de atuação, deve comportar-se tentando maximizar seus interesses, sobretudo os econômicos pessoais indispensáveis para justificar a adequação entre os meios e os fins em consideração.

É importante conceber essa sistemática como uma corrida de reinvenção "quanto à concepção de políticas públicas voltadas ao desenvolvimento econômico" (MATTOS, 2009, p. 104), nova forma de capitalismo de Estado (MUSACHIO, LAZZARINI, P. 35).

MATTOS (2009, p. 105) propõe o seguinte quadro comparativo:

\begin{tabular}{|l|l|l|l|}
\hline Modelos & Estado capitalista & Desestatização & $\begin{array}{l}\text { Estado tomador de } \\
\text { riscos }\end{array}$ \\
\hline Objetivos & $\begin{array}{l}\text { Atuação direta na } \\
\text { produção de bens e } \\
\text { prestação de serviços }\end{array}$ & $\begin{array}{l}\text { Privatização de } \\
\text { empresas estatais. }\end{array}$ & $\begin{array}{l}\text { Compartilhamento de } \\
\text { riscos de investimentos } \\
\text { com iniciativa privada; } \\
\text { alocação eficiente de } \\
\text { capital em setores da }\end{array}$ \\
\hline
\end{tabular}

\footnotetext{
${ }^{6}$ Esse estudo não analisa o tema atinente ao controle (interno e externo) das companhias privadas com acionista estatal sem poder de controle, mas consideramos prudente a adoção de medidas de compliance.
} 


\begin{tabular}{|l|l|l|l|}
\hline & & & $\begin{array}{l}\text { indústria visando } \\
\text { aumento de } \\
\text { competitividade. }\end{array}$ \\
\hline Instrumentos & $\begin{array}{l}\text { Investimento estatal } \\
\text { para o } \\
\text { desenvolvimento de } \\
\text { setores da economia } \\
\text { em concorrência ou } \\
\text { substituindo empresas } \\
\text { privadas }\end{array}$ & $\begin{array}{l}\text { Venda de ativos das } \\
\text { empresas estatais; } \\
\text { contratos de concessão. }\end{array}$ & $\begin{array}{l}\text { Investimentos públicos } \\
\text { em fundos de venture } \\
\text { capital, private equity } \\
\text { e subscrição de ações } \\
\text { nas empresas privadas; } \\
\text { joint ventures } \\
\text { cooperativas, entre } \\
\text { instituições estatais e } \\
\text { empresas privadas; } \\
\text { compartilhamento de } \\
\text { ativos e direitos de } \\
\text { propriedade. }\end{array}$ \\
\hline $\begin{array}{l}\text { Arranjos jurídicos } \\
\text { institucionais. }\end{array}$ & $\begin{array}{l}\text { Empresas públicas } \\
\text { criadas por lei; } \\
\text { monopólios legais } \\
\text { estabelecidos por Lei; } \\
\text { planejamento } \\
\text { econômico (top down). }\end{array}$ & $\begin{array}{l}\text { Transferência da } \\
\text { propriedade e/ou da } \\
\text { gestão de ativos } \\
\text { públicos para empresas } \\
\text { privadas; regulação } \\
\text { econômica (top down). }\end{array}$ & $\begin{array}{l}\text { Política industrial } \\
\text { flexível definida por } \\
\text { meio da mobilização } \\
\text { de conjunto de } \\
\text { incentivos e declaração } \\
\text { de prioridades setoriais } \\
\text { na alocação do capital } \\
\text { a partir de demandas } \\
\text { de mercado (botton } \\
\text { up); regulação por } \\
\text { contrato; contratos de } \\
\text { direito privado, } \\
\text { acordos de cooperação } \\
\text { econômica, parcerias } \\
\text { público-privadas. }\end{array}$ \\
\hline
\end{tabular}

MARQUES NETO (2006, p. 74) destaca que a diferenciação da intervenção teria importância didática, importando "o objetivo visado com a participação - se fiscalização ou incentivo da atividade explorada pela iniciativa privada ou se a fruição dos produtos e lucros obtidos através da exploração da atividade".

Contudo, a fiscalização não exige assunção de risco, o qual se justifica pelo lucro.

Neste ponto, adiro à abordagem de SCHWIND (2017, p. 146), que, ao contrário de limitar os motivos de escolha pelo figurino empresarial adotado pelo Estado às funções sociais, assistenciais ou de controle, acena em sentido realista à empresa, importante para evitar "distribuições de favores a quem parecer conveniente" (MELLO, 2011):

Na realidade, a reunião de sócios privado e entes estatais em uma sociedade de capital misto significa o reconhecimento pela ordem jurídica de que os interesses privados podem ser levados em consideração no âmbito da atuação empresarial do Estado. O agrupamento de capitais públicos e 


\section{A INTERVENÇÃO ESTATAL NO MERCADO COMO ACIONISTA DE EMPRESA PRIVADA E A EXIGÊNCIA DO PROCESSO LICITATÓRIO PARA ALIENAÇÃO DA PARTICIPAÇÃO SOCIETÁRIA}

privados - que é possível justamente pelo veículo da empresa - retrata a consagração do princípio associativo, que tem por pressuposto a concepção de que é possível acomodar interesses públicos e privados sem que isso signifique abrir mão das justificativas que levaram o Estado a integrar o quadro societário de uma empresa de capital misto.

Nesse prisma, a rotulação da situação jurídica a partir da "titulação" da companhia da qual o Estado se torna acionista pode ofuscar ou mitigar a realidade empresarial privada que continua plenamente em vigor, razão por que considero dispensável a rotulagem.

O Estado adquire ações. O capital social é da companhia privada e a natureza da sua origem não altera a natureza privada da companhia. Dinheiro da companhia privada, que não se confunde com os sócios, é recurso privado, ainda que tenha origem em ente participante da administração pública. A relação de troca se estabelece entre as ações adquiridas e o capital aportado que passa a ser de propriedade da companhia e, logo, integralmente privado.

Destarte, a tentativa de rotulações da companhia como "empresas público-privadas" (ARAGÃO, 2009), “empresas semiestatais” (SUNDFELD, SOUZA, PINTO, 2011) ou "parceria público-privada de natureza societária" (SCHWIND, 2017, p. 149), inobstante a relevância didática, além de desnecessárias, poderiam, com todo o respeito, ser evitadas, para que a preponderância do regime de direito privado na relação societária então constituída não padeça qualquer possibilidade de dúvida em razão de rotulações semânticas. Nesse sentido, SCHWIND (2017, p. 37) manifesta opção pela expressão mais detalhada "empresa privada com participação estatal", o que realça, de pronto, a soberania do regime de direito privado, apesar de considerar uma forma de "parceria público-privada de natureza societária".

A empresa privada cujo quadro societário é integrado por acionista estatal, sem poder de controle ${ }^{7}$, é, em sua integralidade, empresa privada. O regime de direito público não incide, conforme elucida SCHWIND (2017, p. 308):

Apesar de ter como sócio um ente integrante da Administração Pública e de existirem recursos de origem pública no seu capital, a empresa privada que conte com um ente estatal em seu quadro de sócios não se subordina ao

\footnotetext{
${ }^{7}$ Não é objeto deste artigo a análise detalhada do poder de controle na companhia, mas nos filiamos à concepção de COMPARATO, SALOMÃO FILHO (2005, p. 51) baseada na "dissociação entre a propriedade acionária e poder de comando empresarial", razão pela qual é considerado, para efeito deste estudo, que o ente estatal integrante da companhia privada não assumiu, sob nenhuma forma ou instrumento, poder de controle segundo o teor do artigo 116 da Lei 6.404/76: "Entende-se por acionista controlador a pessoa, natural ou jurídica, ou o grupo de pessoas vinculadas por acordo de voto, ou sob controle comum, que: a) é titular de direitos de sócio que lhe assegurem, de modo permanente, a maioria dos votos nas deliberações da assembléia-geral e o poder de eleger a maioria dos administradores da companhia; $e$ b) usa efetivamente seu poder para dirigir as atividades sociais e orientar o funcionamento dos órgãos da companhia".
} 
regime de direito público. Nem sequer integra a Administração Pública, sendo que o sócio estatal não tem preponderância no seu controle.

O próprio artigo 37, inciso XX, da Constituição Federal respalda essa constatação ao permitir que o Estado pode participar de "empresa privada", deixando clara a inocorrência da "publicização" da empresa privada por força da participação estatal.

Filiam-se a esse entendimento FIDALGO (2017, p. 120): “a criação de subsidiárias ou a participação em sociedades privadas por empresas estatais [...] constitui uma decorrência da lógica empresarial, sendo, portanto, operações inerentes à adoção do formato societários de direito privado"; GUEDES (2015, P. 75): "as empresas participadas permanecem no âmbito da iniciativa privada"; JUSTEN FILHO (2013, p. 274): "se a participação de uma entidade administrativa acarretasse a automática submissão do sujeito ao regime de direito público, seria desnecessária a existência do inc. XX do art. 37. Bastaria existir o inc. XIX”; SANTOS (2015, p. 64): “[...] se elas não são estatais nem integram a Administração Indireta, não há que se falar em aplicação do regime jurídico de direito público a elas"; SUNDFELD, SOUZA, PINTO (2011, p. 90): "É correto dizer que sobre elas não incide em bloco o regime jurídico das empresas estatais, pois elas de fato não são empresas estatais e não faz sentido querer transpor para elas um regime impróprio"; ARAGÃO (2009, p. 33): “O objetivo do presente artigo é, portanto, verificar quais as modalidades de controle publicísticos eventualmente incidentes sobre a criação e gestão das referidas empresas, uma vez que tratam-se de entidades de caráter privado e exógenas à Administração Pública [...]”.

O Tribunal de Contas da União, no processo TC 003.330/2015-0, examinando tema a respeito da contratação direta, sem licitação, de empresa privada com participação do Estado, proferiu relevante decisão sobre a preservação do regime de direito privado neste arranjo e considerou que a participação estatal minoritária não transforma a sociedade em controlada pela Administração Pública, mas se "trata de uma empresa privada como qualquer outra, com uma única peculiaridade: entre seus sócios minoritários, está uma entidade estatal”:

As características fundamentais na atuação de empresas público-privadas residem na ausência de integração no âmbito da Administração Pública, na inexistência de desempenho de função estatal de qualquer natureza e na não aplicação dos princípios próprios do direito público. Assim, é da natureza da constituição de uma empresa público-privada que essa se baseie exclusivamente na existência de um empreendimento privado. Todos os benefícios a serem produzidos dependem do seu enquadramento no regime de direito privado. 


\section{A INTERVENÇ̃̃O ESTATAL NO MERCADO COMO ACIONISTA DE EMPRESA PRIVADA E A EXIGÊNCIA DO PROCESSO LICITATÓRIO PARA ALIENAÇÃO DA PARTICIPAÇÃO SOCIETÁRIA}

Logo, a atuação do Estado por meio da participação em empresa privada vincula-se a uma lógica empresarial de direito privado. Mas o ente estatal acionista não se desvincula da Administração Pública. Se a empresa privada, de que é acionista, continua sob a regência do regime de direito privado, livre das amarras do direito público nas relações desempenhadas, o ente estatal acionista, por identidade de pensamento, continua vassalo do regime de direito público, no que tange às suas relações específicas, sobretudo à licitação (art. 37, XXI, e 173, § $1^{\text {o }}$, III, da Constituição Federal). A doutrina destaca: "essas entidades estão obrigadas a realizar suas licitações e contratações de obras, serviços, compras e alienações, com observância dos princípios da administração pública” (DALLARI, 2002, p. 72).

Nesse panorama, considerando que a participação estatal na empresa privada não tem como perspectiva a perenidade, resta, ainda saber se a alienação das ações que o ente público detém na empresa privada deveria se submeter ao processo licitatório ${ }^{8}$. Com efeito, as atividades de fomento têm por característica a temporariedade, de modo que o ente estatal, cumprido o seu desígnio, não permaneceria vinculado vitaliciamente.

Frise-se que o artigo 17, II, “c”, da Lei 8.666/93 dispensa a licitação para a "venda de ações, que poderão ser negociadas em bolsa, observada a legislação específica", mas, na hipótese específica em exame, as ações não podem ser negociadas em bolsa ${ }^{9}$.

O artigo 29, inciso XVIII, da Lei 13.303/2016, prevê: “É dispensável a realização de licitação por empresas públicas e sociedades de economia mista: na compra e venda de ações, de títulos de crédito e de dívida e de bens que produzam ou comercializem”. Embora se possa dizer que a limitação fixada pela expressão "que produzam ou comercializem" esteja atrelada aos bens, e não às ações, cremos que a interpretação sistemática e restritiva seria no sentido oposto, autorizando a dispensa da licitação nas operações de compra e venda no mercado de capitais realizadas como objetivo social. Logo, a dispensa não se enquadra na situação sub examine, porque as ações adquiridas para participação em empresa privada não são valores mobiliários comercializados pelo ente público. Importante mencionar que o artigo 28, caput, da Lei 13.303/2016, confirma a obrigatoriedade da licitação para aquisição e alienação de bens e ativos integrantes do respectivo patrimônio da empresa pública ou sociedade de economia mista, situação que reflete diretamente na modalidade de atuação do Estado objeto de análise no presente estudo e prevista no artigo $1^{\circ}$, § $7^{\circ}$, da Lei 13.303/2016.

\footnotetext{
${ }^{8}$ Considera-se inexiste previsão legal específica sobre regime diferenciado de licitação.

${ }^{9}$ A possibilidade de alienação em mercado de balcão ultrapassa o objeto da análise desse estudo.
} 
A necessidade do processo licitatório para alienação das ações do Estado relativas à participação na companhia, a um só tempo, invalidaria as cláusulas do acordo de acionistas as quais autorizam alienação das ações à revelia da licitação (direito de preferência, tag along e put option), bem como constituiria fator de desestímulo a esse arranjo jurídico-societário. Não é difícil imaginar a infelicidade do acionista privado em se encontrar na contingência ou de ter um sócio indesejado, destituído de affectio societatis, quiçá concorrente, ou de se submeter a um leilão imprevisível para arrematar as ações do sócio estatal. É provável que o empresário particular, ciente desse risco, abdicasse do arranjo societário em exame, embora vantajoso para o Estado, para o particular e para a sociedade.

A doutrina examina a necessidade de licitação para o ingresso do Estado na empresa privada, isto é, para a aquisição da participação acionária. ARAGÃO (2009, p. 59) e SOUTO (2004, p. 156) apontam a affectio societatis como fator impeditivo da realização da licitação para a aquisição da participação acionária na hipótese. Mas, para a alienação, com a saída da empresa privada, esse óbice não haveria para o ente estatal que se despede. AMARAL (2007, p. 4) refere-se à figura do contrato de direito privado na administração pública também como elemento que afastaria a exigência da licitação. Mas, para a alienação das ações essa figura não obstaria a exigência de licitação. BANDEIRA DE MELLO (2004, p. 148) repudia a dispensa de licitação nessa hipótese, pois os princípios da Administração Pública impedem, a um só tempo, os administradores de entregar a quem desejem os negócios a serem travados com particulares e o Estado deve sempre buscar a proposta mais vantajosa. $\mathrm{O}$ artigo $28, \S 3^{\circ}$, II, Lei 13.303/2016 determina que "nos casos em que a escolha do parceiro esteja associada a suas características particulares, vinculada a oportunidades de negócio definidas e específicas, justificada a inviabilidade de procedimento competitivo”. A previsão legal é relevante para o ingresso do ente estatal na empresa privada, mas não se aplica para a alienação das ações.

Vale dizer, as razões apontadas para a dispensa da licitação para escolha do parceiro privado, que não é objeto de exame neste estudo, não são oponíveis para a despedida desse parceiro com a retirada do Estado da empresa privada. Ademais, as hipóteses de dispensa e de inexigibilidade previstas nos artigos 24 e 25 da Lei 8.666/93, cada vez mais consideradas de forma excepcional e restritiva, também não acodem à situação em exame ${ }^{10}$. Afinal, a alienação de bens do ativo efetiva-se com base no critério de maior preço, inexistindo, salvo melhor juízo, motivos objetivos e legais plausíveis para a inviabilidade do certame.

\footnotetext{
${ }^{10}$ A premissa adotada por este estudo é que a alienação ocorreria para particulares.
} 


\section{A INTERVENÇ̃̃O ESTATAL NO MERCADO COMO ACIONISTA DE EMPRESA PRIVADA E A EXIGÊNCIA DO PROCESSO LICITATÓRIO PARA ALIENAÇÃO DA PARTICIPAÇÃO SOCIETÁRIA}

Por outro lado, o artigo $2^{\circ}$ da Lei 8.666/93, em harmonia com a Constituição Federal, determina que as alienações serão necessariamente precedidas de licitação.

Enfim, a Lei 13.303/2016 perdeu a oportunidade de regulamentar a questão sobre a alienação das ações detidas por força da participação em empresa particular, considerando a preponderância do regime de direito privado nesse arranjo societário e a sua finalidade, como demonstrado. Não há elementos suficientes que permitam superar a exigência de licitação para a alienação das ações adquiridas pelo ente público, integrante da Administração Pública, para participação em empresa privada, diante da ausência de previsão legal de dispensa ou de inexigibilidade nesta hipótese em análise, apesar da incompatibilidade econômica e realista do procedimento licitatório com a atuação e dinâmica do direito empresarial.

\section{3 - CONSIDERAÇÕES FINAIS}

O Estado pode participar como acionista de empresa privada, devendo motivar a sua opção por essa técnica de intervenção e perseguir objetivos econômicos vantajosos aliados ao interesse coletivo subjacente e atrelados à finalidade de excelente gestão de recursos públicos.

O regime jurídico aplicável às relações da empresa privada em que ingressa acionista estatal minoritário e sem poder de controle é o de direito privado.

A empresa privada com sócio estatal não passa a integrar a Administração Pública.

A alienação de ativos e de bens integrantes do patrimônio de empresas públicas e de sociedade de economia mista, bem como suas subsidiárias, exige a licitação. A ações detidas pelo ente estatal na empresa privada só podem ser alienadas por meio de licitação, à mingua de previsão legal que excepciona o disposto no artigo 37, XXI, da Constituição Federal.

A Lei 13.303/2016 perdeu a oportunidade de regulamentar a questão sobre a alienação das ações detidas por força da participação em empresa particular, considerando a preponderância do regime de direito privado nesse arranjo societário e a sua finalidade, como demonstrado. Não há elementos suficientes que permitam superar a exigência de licitação para a alienação das ações adquiridas pelo ente público, integrante da Administração Pública, para participação em empresa privada, diante da ausência de previsão legal de dispensa ou de inexigibilidade nesta hipótese em análise, apesar da incompatibilidade econômica e realista do procedimento licitatório com a atuação e dinâmica do direito empresarial.

\section{4 - REFERÊNCIAS}


AMARAL, Antonio Carlos Cintra do. Formação de consórcio - escolha de parceiro por empresa estatal - desnecessidade de licitação. Revista Eletrônica de Direito Administrativo Econômico - REDAE, n. 11, ago./out. 2007.

ARAGÃO, Alexandro Santos de. Empresa público-privada. Revista dos Tribunais. v. 890, Dez. 2009.

BANDEIRA DE MELLO, Celso Antonio. Empresa estatal - associação com empresa privada sem licitação para constituírem sociedade de propósitos específicos que disputará licitação de concessão de serviço público - invalidade - inconstitucionalidade do art. 32 e \$§ da Lei 9.074/95. Revista Trimestral de Direito Público - RTDP, n. 48, 2004. COMPARATO, Fabio Konder; SALOMÃO FILHO, Calixto. O poder de controle na sociedade anônima. $4^{\text {a }}$ ed. Rio de Janeiro: Forense, 2005.

DALARIA, Dalmo de Abreu. Licitações nas empresas estatais. Revista de Direito Administrativo - RDA, n. 229, jul./set. 2002.

FIDALGO, Carolina Barros. O Estado empresário. São Paulo: Almedina, 2017.

GUEDES, Filipe Machado. A atuação do Estado na Economia como Acionista Minoritário.

São Paulo: Almedina, 2015.

JUSTEN FILHO, Marçal. As empresas privadas com participação estatal minoritária.

Revista de Direito Administrativo Contemporâneo - ReDAC, ano 1, vol. 2, set./out. 2013.

MARCON, Giuseppe. Le imprese a partecipazione pubblica: finalitá pubbliche ed economicità. Padova: Cedam, 1984.

MARQUES NETO, Floriano Azevedo. A nova regulação estatal e as agências

independentes. Direito administrativo econômico. São Paulo: Malheiros, 2006.

MATTOS, Paulo Todescan Lessa. O sistema jurídico-institucional de investimentos públicoprivados e inovações no Brasil. Revista de Direito Público da Economia - RDPE, ano 7, $\mathrm{n}^{\circ}$ 28, out./dez. 2009.

MAZZUCATO, Mariana. O Estado empreendedor: desmascarando o mito do setor público vs. setor privado. São Paulo: Portofolio Penguin, 2014.

MELLO, Rafael Munhoz de. Atividade de fomento e o princípio da isonomia. Revista

Eletrônica de Direito Administrativo Econômico - REDAE, Salvador, 2011.

MUSACCHIO, Aldo. LAZZARINI, Sergio G. Reinventando o capitalismo de estado: o

Leviatã nos negócios: Brasil e outros países. São Paulo: Portofolio Penguin, 2015.

RODRIGUES, Nuno Cunha. Golden Shares. As empresas participadas e os privilégios do Estado enquanto acionista minoritário. Coimbra: Coimbra Editora, 2004.

SANTOS, Murillo Giordan. Controle das empresas semiestatais. RIL Brasília a. 52 n. 208 out./dez. 2015.

SCHWIND, Rafael Wallbach. O Estado acionista. São Paulo: Almedina, 2017.

SOUTO, Marcos Jurema Vilela. Direito administrativo em debate. Rio de Janeiro: Lumen Juris, 2004.

SUNDFELD, Carlos Ari; SOUZA, Rodrigo Pagani de; PINTO, Henrique Motta. Empresas semiestatais. Revista de Direito Público da Economia - RDPE, Belo Horizonte, ano 9, n. 36, out./dez. 2011. 